\title{
Transanal total mesorectal excision: current updates
}

\author{
Raymond Yap, John Monson \\ Center for Colon \& Rectal Surgery, Florida Hospital, Orlando, FL 32804, USA.
}

Correspondence to: Dr. John Monson, Center for Colon\& Rectal Surgery, Florida Hospital, 2415 North Orange Avenue, Suite 300 Orlando, Orlando, FL 32804, USA. E-mail: john.monson.md@flhosp.org

How to cite this article: Yap R, Monson J. Transanal total mesorectal excision: current updates. Mini-invasive Surg 2019;3:3. http://dx.doi.org/10.20517/2574-1225.2018.57

Received: 14 Aug 2018 First Decision: 12 Nov 2018 Revised: 7 Jan 2019 Accepted: 14 Jan 2019 Published: 13 Feb 2019

Science Editor: Gordon N. Buchanan Copy Editor: Cui Yu Production Editor: Huan-Liang Wu

\begin{abstract}
Transanal total mesorectal excision (TaTME) is the latest in a long list of developments in the surgical treatment of low rectal cancer. This article describes the evolution of the technique, a brief summation of the technical procedure, the current literature into its results, and the possible future direction that it might take. It is the authors' opinion that TaTME will form another technique within the modern colorectal surgeon's armament.
\end{abstract}

Keywords: Transanal total mesorectal excision, transanal, rectal cancer

\section{INTRODUCTION}

The evolution of dedicated surgical techniques in the treatment of rectal cancer over the past century is one of fascinating progress. The concept of the total removal of the mesocolon as described by Miles ${ }^{[1]}$ is the foundation of one of the most important principles in rectal cancer surgery today; that is the complete removal of both the primary cancer and any associated lymph nodes. Heald et al. ${ }^{[2]}$ then emphasized the idea of the "holy plane", when he described total mesorectal excision as sharp dissection along a definable avascular tissue plane to remove the rectum and the mesorectum in an intact envelope.

The achievement of this goal in rectal surgery is often not straightforward. Obtaining adequate transabdominal access to the deep pelvis for cases of mid to low rectal cancer continues to challenge even the most experienced of colorectal surgeons. This is made more difficult in a subset of patients, namely those who are obese, male, and with a narrow pelvis. Numerous techniques over the years have been developed to try and combat these challenges, although usually without overwhelming success or widespread adoption.

\footnotetext{
(@) (-)

(C) The Author(s) 2019. Open Access This article is licensed under a Creative Commons Attribution 4.0 International License (https://creativecommons.org/licenses/by/4.0/), which permits unrestricted use, sharing, adaptation, distribution and reproduction in any medium or format, for any purpose, even commercially, as long as you give appropriate credit to the original author(s) and the source, provide a link to the Creative Commons license, and indicate if changes were made.
}

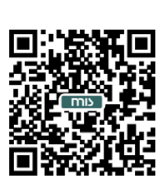


Transanal total mesorectal excision (TaTME) is the latest innovation that aims to overcome these significant limitations in rectal cancer surgery. It has its roots in 1984, when Buess et al. ${ }^{[3]}$ described transanal endoscopic microsurgery (TEMs) using a fixed rectoscope platform that improved both visibility and extended the extent of the surgical field. Although expensive, this technique resulted in more negative margins and less fragmentation of the specimen when compared to conventional transanal excision. Further development of minimally invasive and advanced endoscopic platforms such as transanal minimally invasive surgery (TAMIS) ${ }^{[4]}$ and the ability to create and maintain pneumorectum led finally to the development of the TaTME for en-bloc resection of rectal cancers as first described by Sylla et al.$^{[5]}$ in 2009 . Indeed, it is the development of $\mathrm{CO}_{2}$ insufflation for the rectum using the AirSeal device (CONMED Corp., Utica, NY) with sufficient smoke evaluation that brings the most significant progression from TEMs/TAMIS to TaTME.

The implementation of novel technical and technologic innovations in surgery has often been fraught with unintended consequences. With an emphasis on safety and acceptability of clinical outcomes, the lessons learned from missteps arising throughout the implementation of minimally invasive surgery in other fields (e.g., laparoscopic cholecystectomy and bile duct injury) have justifiably led the surgical community to heed the cautionary tales of early adopters. The technical complexity of TaTME, in addition to the identification of new or rarely-seen anatomic landmarks and planes have led to the occurrence of otherwise rare complications such as urethral injury. This has led to reflection and delay in the dissemination in the technique.

This paper aims to provide a summary of the indications, considerations, surgical technique and evidence for TaTME. It will assume a certain amount of prior knowledge in the treatment of rectal cancer, where areas such as pre-operative staging and standard treatment modalities will be only briefly mentioned.

\section{PREOPERATIVE EVALUATION}

A thorough evaluation of the recently diagnosed rectal cancer patient is of the utmost importance to determine an appropriate treatment plan. This evaluation includes a complete history and physical examination, including digital rectal exam and rigid proctoscopy. Preoperative work-up should include a full colonoscopy to rule out any synchronous lesions. A baseline carcinoembryonic antigen level should be obtained prior to treatment as a prognostic tool and for post-treatment surveillance. A variety and combination of radiographic studies can be performed preoperatively with a different associated benefit profile for each study. Computed tomography (CT), magnetic resonance imaging (MRI), endoanal ultrasound (EUS), positron emission tomography (PET) and PET-CT may be used depending on the clinical situation.

Of these, pelvic MRI is of most interest when considering cases for TaTME. These should be done with the use of a pelvic-specific coil and thin-sectioned, multiplanar T2-weighted images ${ }^{[6-8]}$. MRI is the best current modality for determining the extent of locally advanced tumors, identifying the mesorectal fascia/the circumferential resection margin (CRM), and is at least equal to EUS for the staging of mesorectal lymph nodes $^{[9-11]}$. However, the breath of anatomical information provided by MRI also allows for preoperative planning in TaTME cases. Careful study of the pre-operative MRI can help the surgeon consider how to proceed at difficult points in the operation. Attention should be taken to path of the mesorectal fascia which is clearly delineated on MRI. As orientation can be challenging intra-operatively, identifying the angle by which the mesorectum first dives posteriorly and then curves anteriorly may help the surgeon stay within the correct plane. Further attention should be drawn to where the CRM may be threatened by tumor during the operation.

TaTME was developed to aid in the challenging mid to low rectal cancer cases, although precise definition of its indications has not been fully evaluated. A recent consensus statement was published which listed the following indications for TaTME: (1) male gender; (2) narrow and/or deep pelvis; (3) visceral obesity and/ or a body mass index (BMI) $>30 \mathrm{~kg} / \mathrm{m}^{2}$; (4) prostatic hypertrophy; (5) a tumor height $<12 \mathrm{~cm}$ from the anal 
verge; (6) a tumor diameter $>4 \mathrm{~cm}$; (7) distortion of tissue planes secondary to neoadjuvant radiotherapy; and (8) an impalpable, low primary tumor requiring accurate placement of the distal resection margin ${ }^{[12]}$. They listed their contradictions as obstructing rectal tumours, emergency presentations and T4 tumors. It is noted that many surgeons have used thinner female patients who have not undergone neoadjuvant chemoradiotherapy as part of their learning curve. This is likely due to the fact that planes may be easier to identify, the risk of urethral injury is possibly lower, and salvage from a conventional top-down approach is more straightforward.

\section{SURGICAL APPROACH}

A brief description of the surgical technique will be listed below.

\section{Equipment}

It is assumed that equipment required for an open and laparoscopic low anterior resection is readily available. Specialized equipment for this technique which the authors use include: (1) GelPoint Path Transanal Access Platform (Applied Medical, Inc., Rancho Santa Maragarita, CA); (2) AirSeal Access Port (CONMED Corp., Utica, NY); (3) Articulating hook diathermy (SILS hook, Medtronic, Minneapolis, MN).

We acknowledge that other platforms do exist and are also currently in development.

\section{Preparation}

All patients are given full mechanical bowel preparation. Standard pre-operative procedures such as antibiotics, urinary catheter and deep vein thrombosis prevention are assumed. The patient is placed in stirrups in the modified Lloyd-Davies position. Preparation of the abdomen and perineum should include washing out of the vagina and rectum with betadine.

\section{Technique}

The operation may begin trans-anally, transabdominally or simultaneously from both approaches with two surgical teams. The benefit of a simultaneous approach is that it is associated with significantly reduced operating duration. If a simultaneous approach is embarked upon, there must be two separate scrub setups and two laparoscopic towers/insufflators. Even in the single surgeon situation, two separate setups and laparoscopic towers is recommended to aid transition between the two. The TaTME dissection can be performed with the surgeon standing or sitting. However, if the surgeon stands, better ergonomic access is afforded to the assistant as they try to fit under the patient's right leg.

We routinely set the patient up as if having a laparoscopic total mesorectal excision. This includes some kind of strapping to the chest, and use of gelfoam mat to ensuring the patient does not slide during the operation. We do not routinely use a bean-bag.

Firstly, a purse-string suture (2/0 prolene) is placed with sufficient margin distal to the tumor. This can be achieved transanally with the aid of a Lone-Star and anal retractors if the tumor is low enough [Figure 1]. If the tumor is higher, this can be done by inserting the GelPoint port, and establishing pneumorectum to facilitate suturing through the TAMIS platform. A secure and airtight purse-string suture is mandatory as any defect will allow leakage of tumor content from above, and air into the colon from below. A second lavage with betadine is then performed and the GelPoint port channel inserted if it has not been already. Three ports are inserted into the GelPoint cap at 10 o'clock (Airseal, $8 \mathrm{~mm}$ port), 2 and 6 o'clock (10 $\mathrm{mm}$ working ports). The cap is then secured and pneumorectum is established with the AirSeal device at 10-12 mmHg.

Next, dissection is commenced. A 5 or $10 \mathrm{~mm}$ 30-degree rigid or flexible laparoscope is used for visualization and inserted into the 6 o'clock port. The circumferential intraluminal line is marked out and 


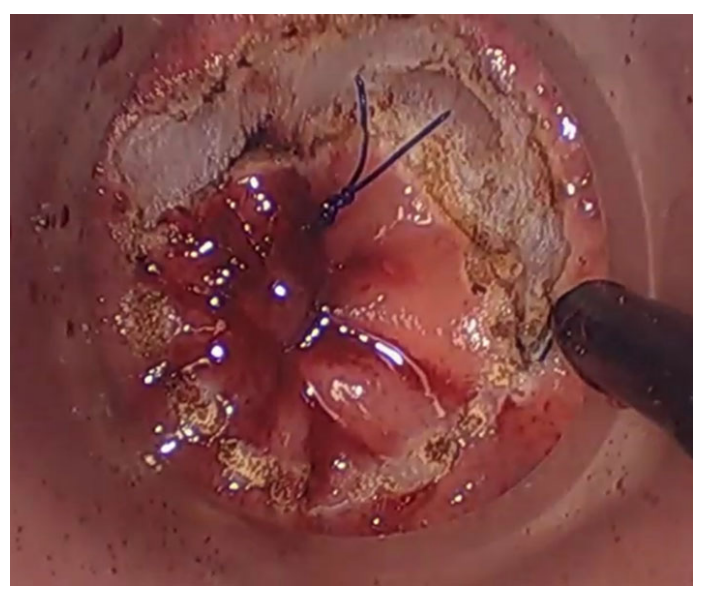

Figure 1. Transanal total mesorectal excision purse-string and proctectomy

full-thickness rectal wall incision performed with hook diathermy. Usually, the dissection is commenced posteriorly as the plane between the presacral fascia and TME envelope is easiest to identify. An important tip is that the rectum is usually pushed away to create more operating space, as opposed to laparoscopically where the colon is usually pulled towards the operator. From this starting point, the dissection is then performed circumferentially, with care taken not to continue in only one or two quadrants which would lead to asymmetrical rectal retraction. Laterally, remaining close to the mesorectal fascia will reduce injury to the pelvic sidewall and the nervi erigentes. Anteriorly, the dissection is in the rectovaginal plane or posterior to Denonvilliers' fascia in males. This dissection may be tailored depending on the position of the invasive portion of the tumor, intentionally proceeding anterior to Denonvilliers' fascia if necessary to secure a clear margin. Another important note is that sometimes an "O" sign appears during dissection in the fatty tissue [Figure 2]; this is an indication that an incorrect plane that is too lateral has been entered ${ }^{[13]}$.

This dissection is then continued up towards the peritoneal reflection. Care must be taken to try and breach the peritoneal cavity as late as possible, as once there is a connection between the two spaces, dissection becomes more difficult due to the bellowing movement of mesorectum as pressures attempt to equalize.

The intraperitoneal dissection is completed either simultaneously or sequentially in the usual fashion with splenic flexure mobilization and high ligation of the inferior mesenteric artery. The colon is either exteriorized and transected through an abdominal incision, or if so desired, the specimen can be delivered trans-anally with the assistance of a wound retractor by transecting the proximal margin laparoscopically with a stapler. Care must be taken if a transanal extraction is attempted; the mesentery of the colon must be divided to ensure that the marginal artery is torn.

A second purse-string is then placed with a 0 or $2 / 0$ prolene in the distal cut end, while an anvil of a circular stapler is secured to the proximal colon. A $19 \mathrm{~F}$ Blakes drain is then cut to approximately $10 \mathrm{~cm}$ and placed on the end of the anvil to facilitate transanal retrieval. Once this is accomplished, the purse-string then being secured around the anvil. The stapler is then engaged and fired in the standard fashion. Other techniques for a stapled end-to-end anastomosis have been described as well as techniques for other types of anastomoses including: hand-sewn coloanal anastomosis and side-to-end stapled anastomosis ${ }^{[14,15]}$.

Although urethral injury is an oft-commented point raised in regards to TaTME, it mainly a concern where the starting point of the dissection is intersphincteric or extremely close to the anorectal ring. Here, as discussed in simulation by Kneist et al.$^{[16]}$, the perineal body is the only structure that protects this area and separates these structures from the rectum. This is due to the fact that the prostate must be mobilized from 


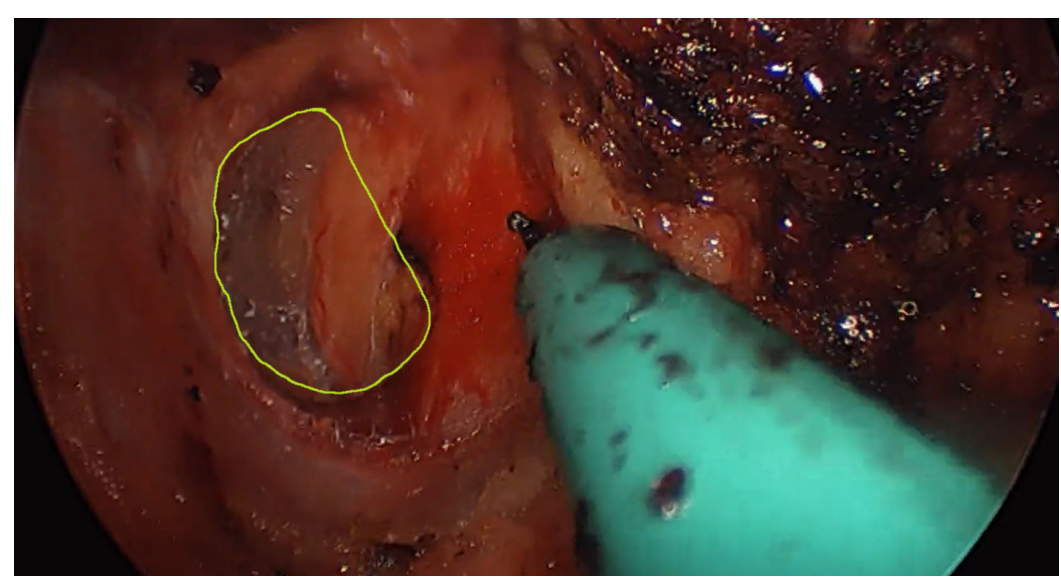

Figure 2. "O" sign. Marked in yellow

Table 1. Steps of the transanal total mesorectal excision

\begin{tabular}{|c|c|c|}
\hline \multicolumn{2}{|r|}{ Bottom (transanal total mesorectal excision) } & Top (intraperitoneal) \\
\hline 1. & Placement of purse-string suture distal to the tumor. & 1. Complete mobilization of the descending and sigmoid colon. \\
\hline 2. & Introduce advanced endoscopic platform transanally. & Splenic flexure mobilization. \\
\hline 3. & Circumferential full-thickness proctotomy. & Inferior mesenteric artery high ligation. \\
\hline 4. & Distal to proximal dissection within the avascular mesorectal plane. & Proximal rectal dissection. \\
\hline \multicolumn{3}{|c|}{ Joint } \\
\hline 5. & \multicolumn{2}{|l|}{ Transection of proximal colon. } \\
\hline 6. & \multicolumn{2}{|l|}{ Securing of proximal anvil and insertion of transanal distal purse string. } \\
\hline 7. & \multicolumn{2}{|l|}{ Passing down of anvil from intraperitoneal to transanal space. } \\
\hline 8. & \multicolumn{2}{|l|}{ Securing of transanal distal purse string. } \\
\hline 9. & \multicolumn{2}{|c|}{ Firing of stapler. } \\
\hline 10. & \multicolumn{2}{|c|}{ Concluding steps (e.g., Leak test, drains, closure) as per conventional technique. } \\
\hline
\end{tabular}

the anterior pelvis for urethral injury to occur. Methods to avoid this in these low dissections are to continue the inter-sphincteric dissection as high as possible in an open fashion, to clearly identify the prostate either endoscopically or in an open fashion, and finally when entering the plane anteriorly, to allow for pneumodissection as this plane will open up once it has been entered. Extreme anterior angles of the port should also be avoided to lessen the risk of this devastating injury.

A brief summary of the steps required for TaTME are demostrated in Table 1.

\section{TRAINING AND DEVELOPMENT}

As mentioned previously, the technical complexity of TaTME and the occurrence of otherwise rare complications should bring pause to any surgeon considering the technique. Proponents of the technique have attempted to set a framework had through which TaTME could be widely adopted in a responsible manner. This was published by the International TaTME Educational Collaborative in $2013^{[17]}$.

Surgeons seeking to develop this technique should have experience with TAMIS or TEMs, as well as open and laparoscopic rectal dissection. It has been suggested a minimum of ten TAMIS or TEMs cases and at least twenty rectal dissections have been completed before embarking on this journey, although these are guidelines only.

Currently, surgeons are encouraged to participate in one or more multi-day courses that are run at expert centers. These involve a structured learning curriculum combining theory sessions, observation of live cases and technical simulation with human cadaveric models. Further education is performed through a number 
of proctored cases where an expert comes to supervise the operating surgeon. Operating room nursing staff have also been encouraged to attend courses to help assist with the implantation of this new technique. Concurrently, there is ongoing collection of data via voluntary registries where surgeons self-report their own experience. This has led to further education through the presentation of this data, alongside cautionary operative videos both at scientific conferences as well as using high quality video streaming.

Although the development of this structured process is to be commended, there are still numerous limitations that surgeons should be aware of. Firstly, this model of education has scant evidence to prove its efficacy in teaching surgical technique. Secondly, participation in the registries is voluntary without stringent audit processes, meaning that the data may not be completely reliable. Thirdly, in the advent of a complication, the use of proctoring in a legal setting is unknown. Although a few papers have proposed possible training models and conducted preliminary evaluations, these have not had the case volume nor full educational assessment or evaluation to make any conclusions on the success or failure of these training models ${ }^{[18-20]}$.

The authors would recommend that the adoption of this technique by any colorectal surgeon should be implemented within units of colorectal surgeons. No surgeon should look to develop this on their own. Two experienced surgeons should be present to form a sounding board for introductory cases. Development of local accreditation processes, audit and a willingness to participate in the current registry are seen as mandatory.

A paper published from our institution suggested that the learning curve on CU-SUM using quality of TME, negative distal resection margin and circumferential resection margin suggested that the learning curve of the case would be approximately $45-51$ cases $^{[21]}$.

\section{RESULTS AND DISCUSSION}

As transanal TME is an emerging technique, long-term oncologic outcomes are not yet available. A variety of series have been published in the literature, using surrogate histopathological parameters such as resection margins and completeness of TME specimen as well as commenting on safety and feasibility.

Numerous papers on oncological outcomes have been released. Perdawood and Al Khefagie ${ }^{[22]}$ compared a cohort of twenty-five patients who underwent TaTME and compared them to a case-matched cohort of patients who had previously undergone laparoscopic TME. All patients in the TaTME group had specimens graded as complete $(80 \%)$ or nearly complete $(20 \%)$, whereas $16 \%$ of the laparoscopic TME specimens were incomplete ${ }^{[22]}$. Similarly, the rate of positive CRM was higher in the laparoscopic TME group (16\%) than the TaTME group (4\%). There were no differences between the two cohorts in length of circumferential resection margin, distal resection margin, number of harvested lymph nodes, tumor status and lymph node status. Another comparison between laparoscopic TME and TaTME found a higher quality mesorectum specimen grade quality in TaTME (96\%) vs. laparoscopic TME $(72 \%)^{[23]}$. A meta-analysis of the available data by Ma et al. ${ }^{[24]}$ showed that TaTME had a decreased rate of a CRM positivity and a higher rate of complete TME grade specimens compared to $\operatorname{TaTME}^{[24]}$.

Short-term outcomes for TaTME have been thoroughly examined and reported in several case reports, case studies and systematic reviews ${ }^{[2-26]}$. Although data is limited to observational studies, this newly developed technique would appear to be safe and feasible based on these early outcomes. A recent systematic review of the published case series posited that the complication rate between TaTME and open or laparoscopic TME are similar ${ }^{[24]}$. Most concerning, however, is the rate of otherwise rare complications such as urethral injury. A recent publication from the TaTME registry using a total of 720 cases were analysed comprising 634 patients with rectal cancer and 86 patients with benign pathology ${ }^{[26]}$. Five urethral injuries were reported at a rate of $0.7 \%$, although this is not a reflection of all TaTME cases done in the world to date. Main risk factors 
appear to be high BMI and a previously irradiated pelvic field. In females, there is also a risk of vaginal injury during the anterior dissection with the subsequent development of a rectovaginal fistula. The same registry study reported a $0.3 \%$ rate of vaginal perforation.

Long-term functional data is not yet readily available, although some short-term studies have been published. Koedam et al. ${ }^{[27]}$ published a prospective quality of life study on thirty patients that showed that at 6 months, TaTME and laparoscopic TME had similar postoperative functional outcomes. It must be noted that TaTME patients in this study had initial (1 month) significant decrease in quality of life, physical and social functioning, fatigue, general experienced pain, anal pain, low anterior resection syndrome and male sexual interest which appeared to recover. A second study by Pontallier et al. ${ }^{[28]}$ also showed no functional difference in bowel habits or urologic function when TaTME was compared to laparoscopic TME.

\section{FUTURE DIRECTIONS}

The most pertinent piece of missing literature is a randomized control trial. The COLOR III trial is designed to fill this gap as a multicenter randomised clinical trial comparing TaTME vs. laparoscopic TME for mid and low rectal cancer. Initially, the CRM rate was chosen as primary endpoint within a superiority design ${ }^{[29]}$; however, the trial was subsequently changed to a non-inferiority design with a clinically relevant primary endpoint of local recurrence rate. This trial is currently in the recruitment phase. However, publication of the recent ALaCaRT (Australasian Laparoscopic Cancer of the Rectum Trial) and ACOSOG (American College of Surgeons Oncology Group) Z6051 trials which examined successful achievement of TME both failed to show non-inferiority of laparoscopy compared to open surgery place some doubt to the use of laparoscopic TME as a gold standard ${ }^{[30,31]}$. The authors anticipate that due to this, the publication of COLOR III will not settle the oncological questions surrounding low rectal cancer surgical technique. Continuing information will come from the registry data and other case series, including 5-year oncological data.

Developments in surgical equipment and in technology may fill the gap. Surgeons have started to attempt a hybrid between TaTME with a robotics platform either for the transanal or intraperitoneal dissection ${ }^{[32]}$. Of most interest is the use of a flexible TEMs platform which may alleviate the many ergonomic and access issues that a single port system such as TAMIS introduces. There have been unpublished reports that surgeons have started experimenting with this system in TaTME.

Further research is needed to define whether TaTME will provide the perioperative, oncological and functional outcomes in low rectal cancer surgery. In addition, further development in the education of both surgeons and trainees is needed to spread this technique if it does prove valuable. It is likely that rather than prove to be a "silver bullet" solution, TaTME will prove another weapon in the armament of the modern colorectal surgeon in dealing with low rectal cancer.

\section{DECLARATIONS}

\section{Authors' contributions}

Concept and design, drafting the manuscript: Yap R, Monson J

\section{Availability of data and materials}

Not applicable.

\section{Financial support and sponsorship}

None.

\section{Conflicts of interest}

All authors declared that there are no conflicts of interest. 


\section{Ethical approval and consent to participate}

Not applicable.

\section{Consent for publication}

Not applicable.

\section{Copyright}

(c) The Author(s) 2019.

\section{REFERENCES}

1. Miles WE. A method of performing abdomino-perineal excision for carcinoma of the rectum and of the terminal portion of the pelvic colon (1908). CA Cancer J Clin 1971;21:361-4.

2. Heald RJ, Husband EM, Ryall RD. The mesorectum in rectal cancer surgery--the clue to pelvic recurrence? Br J Surg 1982;69:613-6.

3. Buess G, Kipfmüller K, Hack D, Grüssner R, Heintz A, et al. Technique of transanal endoscopic microsurgery. Surg Endosc 1988;2:71-5.

4. Atallah S, Albert M, Larach S. Transanal minimally invasive surgery: a giant leap forward. Surg Endosc 2010;24:2200-5.

5. Sylla P, Rattner DW, Delgado S, Lacy AM. NOTES transanal rectal cancer resection using transanal endoscopic microsurgery and laparoscopic assistance. Surg Endosc 2010;24:1205-10.

6. Department of Work and Pensions. Differences in life expectancy between those aged 20, 50 and 80 - in 2011 and at birth. Available from: https://assets.publishing.service.gov.uk/government/uploads/system/uploads/attachment_data/file/223114/diffs_life_ expectancy_20_50_80.pdf. [Last accessed on 23 Jan 2019]

7. Nougaret S, Reinhold C, Mikhael HW, Rouanet P, Bibeau F, et al. The use of MR imaging in treatment planning for patients with rectal carcinoma: have you checked the "DISTANCE"? Radiology 2013;268:330-44.

8. Beets-Tan RG, Lambregts DM, Maas M, Bipat S, Barbaro B, et al. Magnetic resonance imaging for the clinical management of rectal cancer patients: recommendations from the 2012 European Society of Gastrointestinal and Abdominal Radiology (ESGAR) consensus meeting. Eur Radiol 2013;23:2522-31.

9. Al-Sukhni E, Milot L, Fruitman M, Beyene J, Victor JC, et al. Diagnostic accuracy of MRI for assessment of T category, lymph node metastases, and circumferential resection margin involvement in patients with rectal cancer: a systematic review and meta-analysis. Ann Surg Oncol 2012;19:2212-23.

10. Cerny M, Dunet V, Prior JO, Hahnloser D, Wagner AD, et al. Initial staging of locally advanced rectal cancer and regional lymph nodes: comparison of diffusion-weighted MRI with 18F-FDG-PET/CT. Clin Nucl Med 2016;41:289-95.

11. Memon S, Lynch AC, Bressel M, Wise AG, Heriot AG. Systematic review and meta-analysis of the accuracy of MRI and endorectal ultrasound in the restaging and response assessment of rectal cancer following neoadjuvant therapy. Colorectal Dis 2015;17:748-61.

12. Motson RW, Whiteford MH, Hompes R, Albert M, Miles WF, et al. Current status of trans-anal total mesorectal excision (TaTME) following the Second International Consensus Conference. Colorectal Dis 2016;18:13-8.

13. Bernardi MP, Bloemendaal AL, Albert M, Whiteford M, Stevenson AR, et al. Transanal total mesorectal excision: dissection tips using 'O's and 'triangles'. Tech Coloproctol 2016;20:775-8.

14. Bracey E, Knol J, Buchs N, Jones O, Cunningham C, et al. Technique for a stapled anastomosis following transanal total mesorectal excision for rectal cancer. Colorectal Dis 2015;17:O208-12.

15. Hompes R, Guy R, Jones O, Lindsey I, Mortensen N, et al. Transanal total mesorectal excision with a side-to-end stapled anastomosis a video vignette. Colorectal Dis 2014;16:567.

16. Kneist W, Stelzner S, Aigner F, Fürst A, Wedel T. Urethral injury in body donor TaTME training. Coloproctology 2017;39:179-83.

17. Francis N, Penna M, Mackenzie H, Carter F, Hompes R, et al. Consensus on structured training curriculum for transanal total mesorectal excision (TaTME). Surg Endosc 2017;31:2711-9.

18. Atallah SB, DuBose AC, Burke JP, Nassif G, deBeche-Adams T, et al. Uptake of transanal total mesorectal excision in North America: initial assessment of a structured training program and the experience of delegate surgeons. Dis Colon Rectum 2017;60:1023-31.

19. McLemore EC, Harnsberger CR, Broderick RC, Leland H, Sylla P, et al. Transanal total mesorectal excision (taTME) for rectal cancer: a training pathway. Surg Endosc 2016;30:4130-5.

20. Abbott SC, Stevenson ARL, Bell SW, Clark D, Merrie A, et al. An assessment of an Australasian pathway for the introduction of transanal total mesorectal excision (taTME). Colorectal Dis 2018;20:O1-6.

21. Lee L, Kelly J, Nassif GJ, deBeche-Adams TC, Albert MR, et al. Defining the learning curve for transanal total mesorectal excision for rectal adenocarcinoma. Surg Endosc 2018; doi: 10.1007/s00464-018-6360-4.

22. Perdawood SK, Al Khefagie GA. Transanal vs laparoscopic total mesorectal excision for rectal cancer: initial experience from Denmark. Colorectal Dis 2016;18:51-8.

23. Velthuis S, Nieuwenhuis DH, Ruijter TE, Cuesta MA, Bonjer HJ, et al. Transanal versus traditional laparoscopic total mesorectal excision for rectal carcinoma. Surg Endosc 2014;28:3494-9.

24. Ma B, Gao P, Song Y, Zhang C, Zhang C, et al. Transanal total mesorectal excision (taTME) for rectal cancer: a systematic review and meta-analysis of oncological and perioperative outcomes compared with laparoscopic total mesorectal excision. BMC Cancer 2016;16:380.

25. Atallah S, Martin-Perez B, Albert M, deBeche-Adams T, Nassif G, et al. Transanal minimally invasive surgery for total mesorectal excision (TAMIS-TME): results and experience with the first 20 patients undergoing curative-intent rectal cancer surgery at a single 
institution. Tech Coloproctol 2014;18:473-80.

26. Penna M, Hompes R, Arnold S, Wynn G, Austin R, et al. Transanal total mesorectal excision: international registry results of the first 720 cases. Ann Surg 2017;266:111-7.

27. Koedam TW, van Ramshorst GH, Deijen CL, Elfrink AK, Meijerink WJ, et al. Transanal total mesorectal excision (TaTME) for rectal cancer: effects on patient-reported quality of life and functional outcome. Tech Coloproctol 2017;21:25-33.

28. Pontallier A, Denost Q, Van Geluwe B, Adam JP, Celerier B, et al. Potential sexual function improvement by using transanal mesorectal approach for laparoscopic low rectal cancer excision. Surg Endosc 2016;30:4924-33.

29. Deijen CL, Velthuis S, Tsai A, Mavroveli S, de Lange-de Klerk ES, et al. COLOR III: a multicentre randomised clinical trial comparing transanal TME versus laparoscopic TME for mid and low rectal cancer. Surg Endosc 2016;30:3210-5.

30. Stevenson AR, Solomon MJ, Lumley JW, Hewett P, Clouston AD, et al. Effect of laparoscopic-assisted resection vs open resection on pathological outcomes in rectal cancer: the ALaCaRT randomized clinical trial. JAMA 2015;314:1356-63.

31. Fleshman J, Branda M, Sargent DJ, Boller AM, George V, et al. Effect of laparoscopic-assisted resection vs open resection of stage II or III rectal cancer on pathologic outcomes: the ACOSOG Z6051 randomized clinical trial. JAMA 2015;314:1346-55.

32. Kuo LJ, Ngu JC, Tong YS, Chen CC. Combined robotic transanal total mesorectal excision (R-taTME) and single-site plus one-port (R-SSPO) technique for ultra-low rectal surgery-initial experience with a new operation approach. Int J Colorectal Dis 2017;32:249-54. 